\title{
Off-Target Stoichiometric Binding Identified from Toxicogenomics Explains Why Some Species Are More Sensitive than Others to a Widely Used Neonicotinoid
}

Stephen Short, Alex Robinson, Elma Lahive, Amaia Green Etxabe, Szabolcs Hernádi, M. Glória Pereira, Peter Kille," and David J. Spurgeon*,\|

Cite This: Environ. Sci. Technol. 2021, 55, 3059-3069

Read Online

ACCESS | Lلll Metrics \& More | 回 Article Recommendations | sl Supporting Information

ABSTRACT: Neonicotinoids are currently licensed for use in 120 countries, making accurate nontarget species sensitivity predictions critical. Unfortunately, such predictions are fraught with uncertainty, as sensitivity is extrapolated from only a few test species and neonicotinoid sensitivities can differ greatly between closely related taxa. Combining classical toxicology with de novo toxicogenomics could greatly improve sensitivity predictions and identify unexpectedly susceptible species. We show that there is a $>30$-fold differential species sensitivity (DSS) for the neonicotinoid imidacloprid between five earthworm species, a critical nontarget taxon. This variation could not be explained by differential toxicokinetics. Furthermore, comparing key motif expression in subunit genes of the classical nicotinic acetylcholine receptor

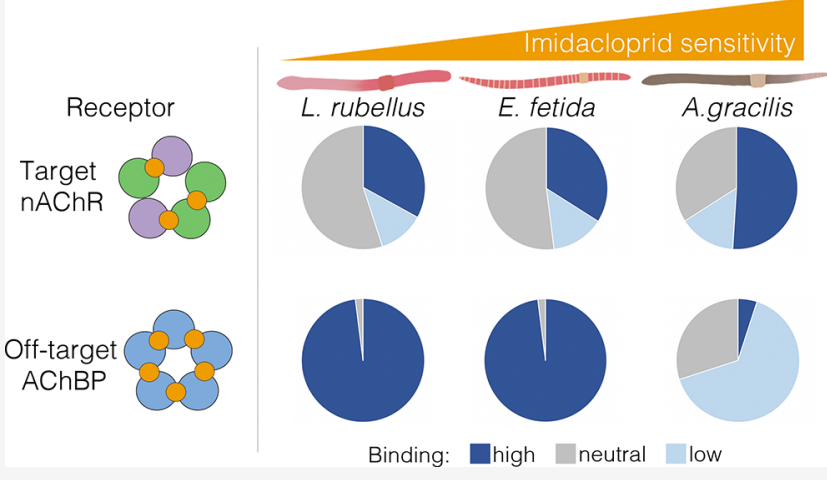
(nAChR) target predicts only minor differences in the ligand binding domains (LBDs). In contrast, predicted dissimilarities in LBDs do occur in the highly expressed but nonclassical targets, acetylcholine binding proteins (AChBPs). Critically, the predicted AChBP divergence is capable of explaining DSS. We propose that high expression levels of putative nonsynaptic AChBPs with high imidacloprid affinities reduce imidacloprid binding to critical $\mathrm{nAChRs}$ involved in vital synaptic neurotransmission. This study provides a clear example of how pragmatic interrogation of key motif expression in complex multisubunit receptors can predict observed DSS, thereby informing sensitivity predictions for essential nontarget species.

KEYWORDS: neonicotinoid, toxicokinetics, toxicodynamics, nicotinic acetylcholine receptor

\section{INTRODUCTION}

Limiting the adverse effects of the $>2 \mathrm{M}$ tonnes/annum of pesticides used globally is of paramount importance for the preservation of ecosystem goods and services. Consequently, there is a critical need to better understand and predict the ecological impacts of pesticides on ecologically important nontarget species. Understanding what drives nontarget species sensitivity to agrochemicals can help to identify the species most at risk.

Neonicotinoids are a class of widely used insecticides that are licensed in 120 countries. Neonicotinoid compounds are known to impact on biomes throughout the globe, including through effects on pollinators, ${ }^{2-4}$ freshwater communities, ${ }^{5}$ and soil organisms. ${ }^{6}$ Differential species sensitivity (DSS) for individual neonicotinoids can range over 7 orders of magnitude. ${ }^{7}$ Differential species sensitivity to pesticides (and other chemicals) is dependent on both toxicokinetic $(\mathrm{TK})^{8}$ and toxicodynamic (TD) traits, ${ }^{9}$ with the former determining the absorption, distribution, metabolism, and excretion
$(\mathrm{ADME})$ and the latter including chemical target receptor orthologue diversity, ${ }^{10}$ ligand binding domain characteristics, and the subsequent downstream adverse outcome pathway responses. $^{11,12}$ The potential effects of pesticides on critical nontarget organisms are often difficult to predict because TK and TD traits (e.g., receptor compliment) are often very poorly described.

Earthworms represent a critical nontarget group that have wide-ranging impacts on soil-based processes and provide vital soil ecosystem services. ${ }^{13}$ By combining classical toxicology with de novo toxicogenomics, we here explain the basis for DSS for the neonicotinoid imidacloprid, the most widely used

Received: July 31, 2020

Revised: December 3, 2020

Accepted: December 9, 2020

Published: February 9, 2021 
insecticide worldwide, both between earthworms and a sequenced insect of known sensitivity (Drosophila melanogaster) and also between five earthworm species tested here. As well as including the standard test species (Eisenia fetida), the chosen earthworm species represent a wide phylogenetic range (i.e., Lumbricidae and Megascolecidae) and multiple ecotypes (i.e., epigeic and endogeic species). Previous to our work, the toxicity of neonicotinoids to earthworms has mainly been assessed in Eisenia fetida. However, studies conducted with insecticides have shown that earthworms can vary in sensitivity, both compared to other soil taxa ${ }^{14}$ and also between species. ${ }^{15}$ Hence, the species in this taxon provide an ideal case study in which to assess the completeness and breadth of our combined approach for attributing a mechanistic cause to the observation of interspecies difference in sensitivity.

Species-specific sensitivity relating to $\mathrm{TD}$ (e.g., receptor) traits can be predicted by receptor analyses that compare primary amino acid sequences, functional domains, and individual residues of target receptors to assess the critical interactions with chemicals and ligand binding domains (LBD). ${ }^{16}$ Imidacloprid causes dysfunction by acting as a partial agonist of the nicotinic acetylcholine receptor (nAChR). ${ }^{17}$ Given that considerable electrophysiological and structural analyses have already identified specific loop sequences and residues critical to $\mathrm{nAChR}$-imidacloprid binding, ${ }^{18-20}$ nAChRs should be particularly amenable to a toxicogenomic predictive approach. Indeed, residue changes identified using electrophysiology that reduce nAChR responses to imidacloprid have been associated with lower imidacloprid sensitivity in ticks and aphids. ${ }^{21,22}$ Therefore, applying a predictive toxicogenomic approach to nAChRs that accounts for amino acid identity and expression in loop residues critical to $\mathrm{LBD}$-imidacloprid interactions has great potential to improve neonicotinoid sensitivity predictions.

\section{MATERIALS AND METHODS}

Study Species and Genotyping. Five earthworm species (four Lumbricidae, Eisenia fetida, Lumbricus rubellus, Aporrectodea caliginosa, and Dendrobaena octaedra; one Megascolecidae, Amynthas gracilis) were tested for imidacloprid sensitivity. E. fetida were taken from an in-house culture, while the remaining species were collected from the field populations in the UK (L. rubellus, A. caliginosa, and D. octaedra) or São Miguel Island, The Azores (A. gracilis) (see the Supporting Information (SI) methods section for site details). Earthworm morphospecies are known to comprise distinct clades for $E$. fetida, ${ }^{23}$. rubellus, ${ }^{24,25}$ A. caliginosa, ${ }^{26}$ and $A$. gracilis ${ }^{27}$ but not D. octaedra. ${ }^{28}$ For this reason, the mitochondrial cytochrome oxidase 1 (CO1) locus was sequenced for 18-20 individuals to assess the population genetic homogeneity. All animals used for transcriptome expression analysis (see below) were also CO1 genotyped (see the SI Methods).

Earthworm Toxicity Testing. The full test method is detailed in the SI Methods. Briefly, tests with the five earthworm species were conducted in a natural soil (Kettering loam) amended with 3\% w/w organic matter (composted bark from LBS Horticultural, Colne, UK). The soil was described in more detail by Robinson et al. ${ }^{29}$ Earthworm numbers per replicate were modified (minimum five individuals per rep) on the basis of their availability from collection and also to avoid crowding effects. ${ }^{30}$ Imidacloprid was spiked as an aqueous solution at seven concentrations (including a control) up to 10 or $30 \mathrm{mg} / \mathrm{kg}$ dry weight soil with four replicates per treatment. The added pesticide was left for $24 \mathrm{~h}$ before the earthworms were added. This preincubation time allowed for an initial chemical binding to soil but avoided the potential for substantial degradation. Spiked horse manure was supplied as food. As the earthworm species differ in their temperature preference, tests were conducted at $20 \pm 2{ }^{\circ} \mathrm{C}$ for E. fetida and A. gracilis and $13 \pm 2{ }^{\circ} \mathrm{C}$ for A. caliginosa, L. rubellus, and $D$. octaedra. These temperatures were selected on the basis of the conditions used in culturing or annual median temperatures at their field collection sites and were chosen to ensure optimal cocoon production while limiting any background control mortality (as can occur at higher temperatures in temperate soil species ${ }^{31}$ ). Earthworm survival was recorded, the laid cocoons were counted after 28 days exposure, and $\mathrm{LC}_{50}$ and $\mathrm{EC}_{50}$-reproduction values were calculated in the $\mathrm{DRC}$ package in $\mathrm{R} 1.2 .13355^{32}$

Imidacloprid Uptake and Distribution. At the end of the test, earthworm tissue and a soil sample were collected for imidacloprid determination. The resource constraints meant that we could not analyze all samples, but instead we had to adopt a targeted approach. For imidacloprid in soil, we measured concentrations in $15 \%$ of samples from across the 28 day sampled soils. An analysis of these samples would provide both confirmation of no gross errors in dosing stock solution preparations (i.e., measured concentration within an order of magnitude of nominal) and also an indication of imidacloprid degradation. A general linear model (GLM) was conducted in Minitab v18 with $\log$ value to assess the concentration and temperature effects on the measured concentrations using concentration and temperature as fixed factors.

Tissue imidacloprid concentrations were measured in the tail samples of two earthworms from each replicate in all treatments for $L$. rubellus to assess uptake over the concentration range. To compare uptake between the species, imidacloprid was measured in two individuals per replicate in the 0 and $0.37 \mathrm{mg} / \mathrm{kg}$ treatments. As the toxicokinetics of imidacloprid was not known, the earthworms were not depurated as this takes $48 \mathrm{~h}$, over which time a proportion of the chemical could have been eliminated. ${ }^{33}$ Hence, the measured concentrations contain both truly internalized chemical and also gut content associated residues. Imidacloprid measurements were conducted on the basis of the study by Woodcock et al. ${ }^{2}$ by liquid chromatography-mass spectrometry (LC-MS) (see the SI Methods). The imidacloprid tissue concentrations between the species were compared. The log transformed data were tested for normality using a Shapiro-Wilk test before performing an one-way analysis of variance (ANOVA) with Tukey's post hoc test in Minitab v18.

Toxicokinetic rates were assessed in time-series radiolabeled imidacloprid uptake and elimination studies with the most sensitive species $A$. gracilis, least sensitive $L$. rubellus, and the standard test species E. fetida (second least sensitive). These species were selected to provide comparisons of earthworms with different and similar sensitivities. Exposures to ${ }^{14} \mathrm{C}$ imidacloprid were conducted in the same soil as the toxicity bioassays with the labeled chemical at $0.0625 \mathrm{mg} / \mathrm{kg}$ (approximately half of the lowest $\mathrm{EC}_{50}$-reproduction), giving an activity of $481 \mathrm{kBq} / \mathrm{kg}$ (see the SI Methods). The activity was measured after tissue homogenization in acetonitrile by following Carter et al. ${ }^{34}$ Individual measurements for each species were fitted without statistical transformation using a 
one compartment TK model to derived the uptake $\left(k_{1}\right)$ and elimination $\left(k_{2}\right)$ rate constants $( \pm S E)$ in GENSTAT. Imidacloprid half-life in tissues $\left(T_{1 / 2}\right)$ and bioaccumulation factors were derived from these $k_{1}$ and $k_{2}$ rates.

To assess the imidacloprid tissue distribution, separate exposures were conducted for 35 individual L. rubellus, E. fetida, and A. gracilis exposed to $0.0625 \mathrm{mg} / \mathrm{kg}{ }^{14} \mathrm{C}$ imidacloprid for $168 \mathrm{~h}$. All earthworms were depurated for $24 \mathrm{~h}$ on wet filter paper before being dissected to obtain nerve cord, seminal vesicle, and post clitellum body wall tissues for scintillation counting. ${ }^{34}$ Samples were pooled to give five replicates each with tissues from seven individuals (see the SI Methods).

Animal Dissection, RNA Isolation, and Transcriptome Production. Tissues were dissected from the same three (CO1 genotyped) earthworms used for the TK study as pairs showing different and similar sensitivities (L. rubellus, five animals; A. gracilis, five animals; E. fetida, six animals) and isolated RNA were prepared and indexed for paired-end multiplexed sequencing (TruSeq Stranded mRNA Library Prep Kit, Illumina, San Diego, California) before being sequenced (150 bp paired-end) using various Illumina sequencing platforms (see the SI Methods). Raw reads were trimmed using Trimmomatic24 (v. 0.36) $)^{35}$ and assembled using Trinity (v. 2.2.0). ${ }^{36}$ An assembly was created for each species using all reads for all tissues in addition to single tissue assemblies. The resulting species lists of contigs from both the all tissue and single tissue assemblies were combined and processed using EvidentialGene: tr2aacds, mRNA Transcript Assembly Software (v. 2017.12.21) ${ }^{37}$ into the most biologically useful "best" set of mRNA and classified into primary and alternate transcripts.

Earthworm nAChR/AChBP Orthologue Identification. Paired reads (L. rubellus 437 million, E. fetida 819 million, A. gracilis 182 million, including $\sim 41$ million $L$. rubellus nerve cord, $\sim 66$ million E. fetida nerve cord and $\sim 66$ million $A$. gracilis nerve cord) were mapped to the transcriptome assembly (RSEM v. 1.3.0), and counts were normalized with weighted trimmed mean of M-values (TMM) to calculate the relative expression levels. Earthworm nAChRs and AChBPs were determined using a Reciprocal Best Hit BLAST method ${ }^{38}$ and sequence alignments, trimming, and trees built using Geneious (v. 9.1.8). Alignments against D. melanogaster $\mathrm{nAChR}$ subunit sequences revealed earthworm sequences containing all loops relevant for acetylcholine/imidacloprid binding (such sequences were termed "full-length").

nAChR/AChBP Interaction Loop Residue Expression. The lists of full-length nAChR $\alpha$, non- $\alpha$, and AChBP subunits were used to determine the expression of specific amino acid residues in interaction loops critical to imidacloprid binding (i.e., residues experimentally associated with differential binding, $\mathrm{EC}_{50}$ or maximal response values). As some earthworm populations are genetically heterologous and some species present higher allelic variation, the transcriptome assembly produces a different number of contig sequences for any given gene or gene family (including $\mathrm{nAChR} \alpha$, non- $\alpha$, and AChBP subunits). This is an issue when comparing the expression between species from genetically homogeneous (e.g., Amynthas gracilis) with heterologous populations (e.g., Lumbricus rubellus). This is because sequencing reads map to a single contig (uniquely mapping reads) and the expression of a given gene will be split across a greater number of distinct contigs in a species with a higher genetic variation. To allow for species comparisons, we clustered all full-length contigs into either nAChR $\alpha$, non- $\alpha$, and AChBP subunits and summed the total normalized expression for each subunit type in each species across each tissue, giving the total expression by tissue for the three subunit types. This approach also allows for comparisons in the expression proportions of specific residue identities (in specific tissues) between species across the subunit types (calculated as percentage of total tissue expression).

Comparative Binding "Affinity" Scores for nAChR and AChBP Subunit Residues. The expression proportions for each residue (associated with binding) in each species was used to create comparative "affinity" and "sensitivity" scores (see the SI Results and Discussion for rules followed at each binding site, full sequences in SI Data S1-S3, and detailed residue quantifications in SI Data S4). Briefly, within a species, the percentage expression (in nerve cord) of residues experimentally associated with higher/lower imidacloprid binding were divided to give a higher/lower binding fraction at each site. For example, if a critical position is represented by a range of nonpolar, polar, and acidic residues across all fulllength $\mathrm{nAChR} \alpha$ subunits, existing information is used to categorize the relationships of the various residues with imidacloprid binding. That is, they are associated with a higher binding or lower binding or, in cases where no confident assignment is possible, were considered to have neutral roles. In this example, if mutational experiments reveal that the replacement of nonpolar or polar residues with acidic residues reduces imidacloprid binding and vice versa (indicated by altered imidacloprid concentrations activating the receptor to half its maximal level), then nonpolar/polar and acidic residues are grouped into higher and lower binding categories, respectively, and their relative expression percentages were used to produce the higher/lower binding fraction for that position. Combining residue identities possessing similar relationships to binding allows for the simultaneous consideration of multiple residue identities at the same position. The exact details of various decisions (and the justifying literature) for each residue across all subunit types are included in SI Data S4. Then, for the earthwormearthworm comparisons, the high/low fractions for each residue in $A$. gracilis were then divided by the mean high/ low fractions for the two lumbricid species. Likewise, the fractions for $D$. melanogaster were divided by the $A$. gracilis values (in the $D$. melanogaster $-A$. gracilis comparison) and by the mean high/low fractions for the two lumbricid species (in the D. melanogaster-lumbricid comparison). These calculations gave a comparative affinity score for each site of interest, where a score $<1=$ relatively greater proportion of high-affinity residues in denominator species and $>1=$ relatively greater proportion of high-affinity residues in numerator species. At sites where there is no obvious higher/lower affinity relationship between residues but the expression of a particular residue is thought to enhance the imidacloprid binding (e.g., structural analysis suggests tyrosine at a site promotes imidacloprid ligand binding), the affinity score is produced directly by dividing the nerve cord residue expression percentages (of tyrosine in this case).

Earthworm nAChRs are assumed to be composed of a 3:2 ratio of $\alpha /$ non- $\alpha$ subunits (see the Supporting Information for discussion and justification of this assumption). Such pentamers are thought to contain three LBDs, two at the $\alpha$ / non- $\alpha$ interfaces and one at the single $\alpha / \alpha$ interface. ${ }^{39}$ This 
means residues within specific loops may not equally contribute to ligand binding. Specifically, while binding-critical residues in loops $\mathrm{A}, \mathrm{B}$, and $\mathrm{C}$ in $\alpha$ subunits are predicted to contribute to all three LBDs, residues in loops G, D, E, and F in $\alpha$ subunits contribute to the single $\alpha / \alpha$ interface (one-third of all LBDs), whereas loops D, E, and F in non- $\alpha$ subunits contribute to both $\alpha /$ non- $\alpha$ interfaces (two-thirds of all LBDs). To account for these differences, the affinity scores were adjusted. Initially, the reciprocal was calculated (1/affinity score) for scores predicting greater proportions of high-affinity residues in any denominator group. Then, the scores for loops $\mathrm{G}, \mathrm{D}, \mathrm{E}$, and $\mathrm{F}$ (if a score was present) in $\alpha$ subunits were adjusted, ([affinity score -1$] \times 0.333$ ), and loops $\mathrm{D}, \mathrm{E}$, and $\mathrm{F}$ in non- $\alpha$ subunits, ([affinity score -1$] \times 0.666)$. No adjustment was made to scores for loops A, B, and C in $\mathrm{nAChR} \alpha$ subunits and all AChBP loops on the basis that they contributed to all LBDs. The subsequent residue scores for interacting loops were combined as follows: Loops associated with multiple residue scores but with all scores indicating higher affinity for either the denominator or numerator species, $[($ sum residue affinity scores $)+1]$. When residue scores for a single loop gave a combination of both higher denominator and numerator species scores, the following steps were taken: first, sum scores for numerator species and denominator species separately. The larger summed value reveals the overall affinity direction for the whole loop (i.e., toward higher affinity in the numerator or denominator species). Then, [(larger value - smaller value $)+1]$. For loops associated with only a single score: $([$ residue affinity score $]+1)$. The $\log _{2}$ values of the resulting loop scores were calculated and represented the final loop affinity score.

Comparative Imidacloprid Sensitivity Scores for nAChR and AChBP Subunit Residues. For nAChR subunits, the affinity scores (prior to the $\log _{2}$ conversion) for all loops in nAChR $\alpha$ and non- $\alpha$ subunits were combined. The loop affinity scores suggesting a higher affinity in the numerator species were summed, as were the loop affinity scores predicting a higher affinity in the denominator species. The category represented by the larger value was taken as the overall sensitivity direction (i.e., higher sensitivity in the numerator or denominator species). The smaller value was then subtracted from the larger value and $\log _{2}$ converted to give the overall comparative $\mathrm{nAChR}$ sensitivity score. The process was completed for AChBP loops but with the exception that the category (either numerator or denominator species) represented by the smaller value was taken as the overall sensitivity direction (on the basis that high binding to an off-target protein reduces sensitivity). The expression of AChBPs critical to the sensitivity score were validated using reverse transcription polymerase chain reaction (RT-PCR) (see the SI Methods).

\section{RESULTS AND DISCUSSION}

Comparative Sensitivity of Earthworm Species. Imidacloprid measurements confirmed the exposure concentrations within an expected range, although indicating up to $35 \%$ biodegradation over 28 days (see Figure S1). GLM analysis confirmed that the measured concentrations were significantly dependent on nominal values $(F=352, P<$ $0.001)$. There was no significant effect of temperature $(F=$ $0.01, p>0.05)$ or any nominal value temperature interaction $(F=0.23, p>0.05)$ on the measured concentrations. This indicates no temperature effects on imidacloprid fate (see Figure S1) that could explain any observed DSS.

$\mathrm{LC}_{50} \mathrm{~s}$ for imidacloprid in the five species varied by a factor of $>14.4$ from the most sensitive $A$. gracilis to the least sensitive L. rubellus and A. caliginosa (Figure 1A). The DSS determined

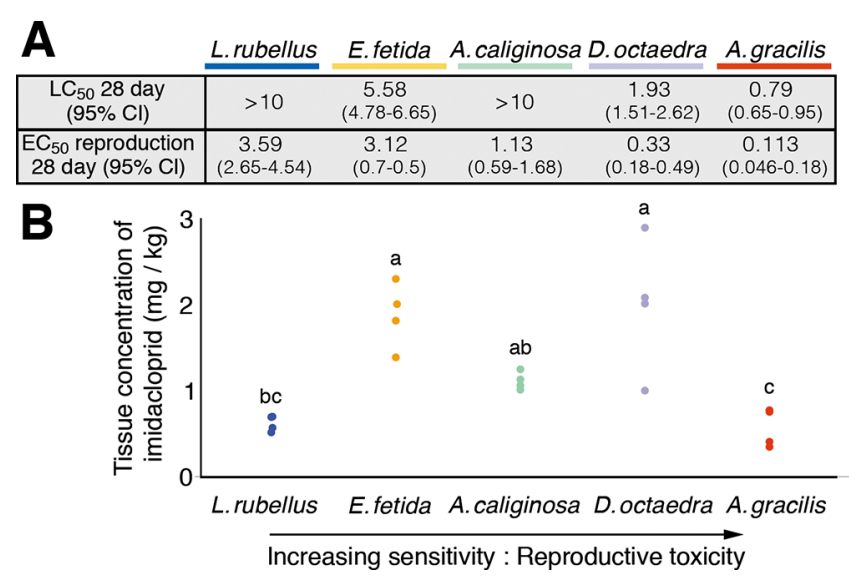

Figure 1. Sensitivity and tissue accumulation of imidacloprid in five earthworm species. (A) Toxicity expressed as the 28 day $\mathrm{LC}_{50}$ and $\mathrm{EC}_{50}$-reproduction (both with $95 \% \mathrm{CIs}$ ) for imidacloprid (milligrams per kilogram of soil) for five earthworm species derived from Probit $\left(\mathrm{LC}_{50}\right)$ and logistic $\left(\mathrm{EC}_{50}\right)$ model fits. (B) Tissue concentrations of imidacloprid in four replicates each with two individuals (when available) of five earthworm species exposed at $0.37 \mathrm{mg} / \mathrm{kg}$ soil; letter indicated difference between treatments (Tukey's Test $p<0.05$ ).

using $\mathrm{EC}_{50} \mathrm{~s}$ for reproduction was broadly consistent with the $\mathrm{LC}_{50}$ values, indicating DSS in the order $A$. gracilis $>D$. octaedra $>$ A. caliginosa $>$ E. fetida $>$ L. rubellus (Figure 1A). Comparatively, A. gracilis was 31.7 -fold more sensitive than $L$. rubellus. Temperature can have a significant effect on toxicity, ${ }^{40,41}$ including on imidacloprid in short-term bioassays (although decreasing with exposure time). ${ }^{42}$ In this study, however, the attribution of species difference to exposure temperature is not supported. For example, the two species tested at $20^{\circ} \mathrm{C}$ (A. gracilis and E. fetida) were found to show a high DSS, being the most sensitive and second least sensitive species. Further, the order and 3-fold difference found here for sensitivity for E. fetida and D. octaedra tested at 20 and $13{ }^{\circ} \mathrm{C}$, respectively, is consistent (indeed in a magnitude slightly less) with the 5-fold difference found at the same test temperature by Kreutzweiser et al. ${ }^{43}$ Hence, exposure temperature clearly cannot explain DSS. We, therefore, looked for a physiological cause.

Toxicokinetics. Imidacloprid in tissues of exposed $L$. rubellus showed tissue/soil bioaccumulation factors of 1.6-2.7 based on nominal concentrations and $2.76-7.51$ based on the final measured soil concentrations. Bioaccumulation factors were lower at the higher exposure concentrations (Figure S2). When exposed at $0.37 \mathrm{mg} / \mathrm{kg}$, the tissue concentrations varied significantly (ANOVA $F=15,34, p<0.001$; Tukey's test, $P<$ 0.05 ) between species (4-fold between the lowest, A. gracilis, and the highest, D. octaedra) (Figure 1B). The ranking of imidacloprid accumulation and magnitude of species difference did not correlate with the sensitivity. Indeed, the most sensitive species, A. gracilis, showed the lowest tissue imidacloprid followed by the least sensitive, L. rubellus (Figure 2A,B). There was a pattern for higher tissue concentrations in smaller (e.g., D. octaedra) rather than larger (e.g., L. rubellus, A. gracilis) 


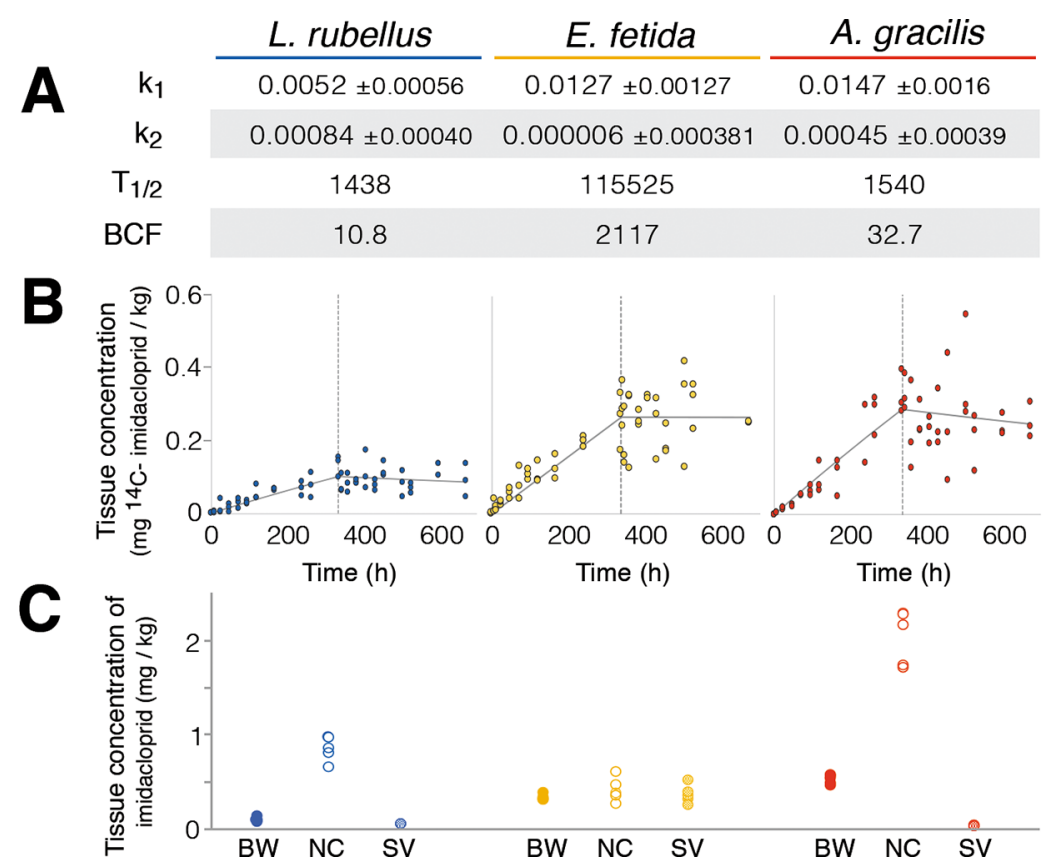

Figure 2. ${ }^{14} \mathrm{C}$-Imidacloprid toxicokinetic and tissue localization in two insensitive lumbricid and one sensitive megascolecid earthworm. (A) Uptake and elimination rate constants $\left(k_{1}, k_{2} \pm \mathrm{SE}\right)$, imidacloprid half-life in tissues $\left(T_{1 / 2}\right)$, and bioaccumulation factors (BAF) from the one compartment TK model fits for three earthworm species. (B) Uptake and elimination of ${ }^{14} \mathrm{C}$-labeled imidacloprid for three earthworm species exposed in soil at a concentration of $0.0615 \mathrm{mg} / \mathrm{kg}$ soil for $336 \mathrm{~h}$, followed by a $336 \mathrm{~h}$ elimination period in clean soil; the broken gray line indicates the start of the elimination period, the circles are measured data points, and the solid line is a one-compartment TK model fit. (C) Tissue localization of ${ }^{14} \mathrm{C}$ imidacloprid in the body wall (BW), nerve cord (NC), and seminal vesicle (SV) of four individuals from three earthworm species exposed at $0.0615 \mathrm{mg} / \mathrm{kg}$ soil for $168 \mathrm{~h}$.

earthworms (Figure 1B). This may be explained by the sizerelated surface area to body mass ratio uptake limitation in the larger species. From this data, we conclude that the DSS cannot be explained by imidacloprid bioaccumulation factors alone.

To investigate the attribution of DSS to TK rates, we conducted ${ }^{14} \mathrm{C}$-imidacloprid uptake and elimination experiments with the most sensitive species $A$. gracilis, the least sensitive L. rubellus, and the standard test species E. fetida (second least sensitive). The accumulation rates $\left(k_{1}\right)$ determined from one compartment TK model fits varied 2.8fold (Figure 2A). The predicted elimination rates were low in all species $\left(k_{2}=6 \times 10^{-5}-4.5 \times 10^{-4} \mathrm{~h}^{-1}\right.$, estimated half-lives $>1000$ days all cases), resulting in near linear uptake and slow loss (Figure 2A,B). Slow earthworm imidacloprid elimination rates contrast with those for the teleost fish Oncorhynchus mykiss - a half-life of 60-70 $\mathrm{h}^{44}$-and amphipod Gammarus pulex-a half-life of $82 \mathrm{~h}^{45}$ Earthworms (E. fetida) have previously shown to have moderate to slow elimination of a range of lipophilic organic compounds-half-lives of 2-28 days ${ }^{46,47}$ - suggesting that earthworms possess a low biotransformation capacity for multiple organic chemicals, including imidacloprid.

The pattern of comparatively high tissue accumulation of imidacloprid by E. fetida and low accumulation by L. rubellus as detected by LC-MS (Figure 1B) was confirmed by radiochemical analysis; however, the kinetic study places $A$. gracilis closer to E. fetida than L. rubellus (Figure 2A,B). The difference in TK traits indicated by the radiolabel and unlabeled LC-MS measurements may provide indications of possible imidacloprid metabolism in species. In L. rubellus, uptake is constrained by the low assimilation rate, as confirmed by tissue measurements. In $A$. gracilis, the assimilation rate is higher but measurements indicate low parent compound concentrations. As the ${ }^{14} \mathrm{C}$-imidacloprid radiolabel is placed in the stable (pyridyl-2,6) ring, this may suggest some degree of metabolic biotransformation by $A$. gracilis with the radiolabel retained as a radiolabeled metabolite. Such metabolism might be expected to reduce sensitivity, which is demonstrably not the case for A. gracilis. For E. fetida, a high assimilation rate leads to high tissue concentrations, but this is not associated with a high sensitivity. The tissue localization of ${ }^{14} \mathrm{C}$ imidacloprid indicates higher concentrations in the putative target nerve cord than in the body wall or seminal vesicle. Nerve cord concentrations are higher in $A$. gracilis, but concentrations in the lumbricids also differ (Figure 2C), which is not consistent with their comparable sensitivities. From these results, we conclude that neither TK dynamics or distributions to critical nerve tissues can wholly explain imidacloprid DSS. This conclusion is in agreement with those of Van Den Berg et al. ${ }^{48}$ and Dalhof et al., ${ }^{49}$ respectively, for the organophosphate chlorpyrifos and pyrethroid cypermethrin. Both of these studies further recommended a greater consideration of TD traits, which was done here through receptor analysis.

Toxicodynamics through Receptor Analysis. We investigated the potential contribution of divergent nAChRs and AChBPs to DSS. This requires consideration of how to convert the nAChR/AChBPs subunit gene sequence and expression differences into sensitivity predictions. The $\mathrm{nAChR}$ consists of $\alpha$ and non- $\alpha$ subunits combined into heteropentamer and $\alpha$ subunit homopentamer conformations ${ }^{17}$ (Figure 3A,B), while AChBPs are homopentamers formed from $\alpha$-like subunits (Figure 3C). ${ }^{50}$ In nAChR hetropentamers, imidacloprid is thought to bind at $\alpha /$ non- $\alpha$ subunit interfaces, as well as the single $\alpha / \alpha$ interface present in 3:2 $\alpha$ / 


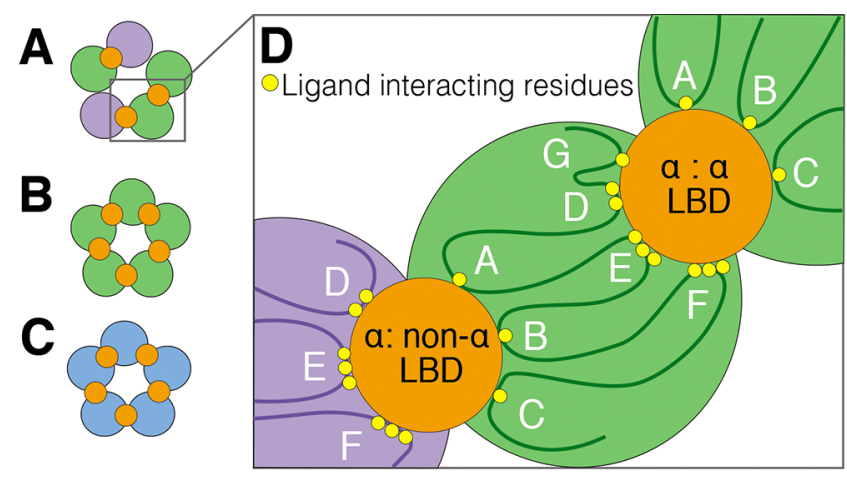

OnAChR a subunit OnAChR non-a subunit $\bigcirc$ AChBP subunit

Figure 3. nAChRs and AChBPs in various pentamer conformations and interaction loops contributing to ligand binding domains (LBDs). (A) Schematic of nAChR heterompentamer with a 3:2 ratio of $\alpha$ / non- $\alpha$ subunits (box shows the region expanded in D), with three LBDs shown as orange circles. (B) Schematic of $\mathrm{nAChR} \alpha$ subunit homopentamer with five LBDs. (C) Schematic of AChBP homopentamer formed of AChBP $\alpha$-like subunits. (D) Enhanced representation of boxed region in A, showing LBDs that form between loops/residues located at $\alpha /$ non- $\alpha$ and $\alpha / \alpha$ subunit interfaces. At $\alpha /$ non- $\alpha$ LBDs, the $\alpha$-subunit provides loops A, B, and C and the non- $\alpha$ subunit provides $\mathrm{D}, \mathrm{E}$, and F. In $\alpha-\alpha$ LBDs, loops $\mathrm{D}, \mathrm{E}$, and $\mathrm{F}$ are provided by the equivalent regions of $\alpha$-subunits (with a further loop, $\mathrm{G}$, potentially playing a role at these LBDs). The LBDs in homopentamers, whether $\mathrm{nAChR}$ or $\mathrm{AChBP}$, occur in a manner similar to the $\alpha-\alpha$ interface shown.

non- $\alpha$ ratio heteropentamers (Figure 3A). ${ }^{39}$ In heteropentamers, each ligand binding domain (LBD) is composed of several interacting loops: A, B, C, and G provided by the $\alpha$ subunit and D, E, and F present on the non- $\alpha$ subunit (Figure 3D). In nAChR or AChBP homopentamers, all interacting loops are provided by the adjacent $\alpha$-subunits (Figure 3D). As non- $\alpha$ subunits lack the necessary loop $\mathrm{C}$ sequences, ${ }^{18}$ they cannot form homopentamers and only create binding sites when adjacent to $\alpha$ subunits with necessary loop sequences. Electrophysiological analyses and structural studies have identified residues in loop sequences critical to nAChRimidacloprid responses. ${ }^{18-20}$ Characterizing the expression of residues across all nAChR subunits is needed to predict functionality and, by extension, DSS.

We produced putative lists of $\mathrm{nAChR} / \mathrm{AChBP}$ subunit sequences from A. gracilis, L. rubellus, and E. fetida transcriptomes by reciprocal best BLAST (short read libraries and transcriptome shotgun assemblies deposited as Genbank BioProject numbers: A. gracilis PRJNA608674, L. rubellus PRJNA608704, E. fetida PRJNA608692, and in SI Data S1S3). This analysis produced 269, 126, and 130 contigs corresponding to nAChR/AChBPs for L. rubellus, E. fetida, and A. gracilis. From these lists, we identified for L. rubellus 94 (69:25 $\alpha /$ non- $\alpha$ subunit) full-length nAChR contigs, E. fetida 77 (58:19 $\alpha /$ non- $\alpha$ subunit), and $A$. gracilis 60 (48:12 $\alpha /$ non- $\alpha$ subunit) full-length $\mathrm{nAChR}$ sequences. The potentially high nAChR orthologue number from the transcriptome is supported by draft genome analyses (not shown) and represents an expanded nAChR subunit repertoire in earthworms relative to other groups (e.g., Caenorhabditis elegans 29, humans 16, and insects 10-12). ${ }^{51,52}$ Like Drosophila melanogaster, earthworm nAChR subunit expression is predominantly in nerve tissues and suggests a $\sim 3: 2$ ratio of $\alpha /$ non- $\alpha$ subunit expression (SI and Figure S3).
Reciprocal best BLAST identified 10, 11, and 10 AChBP subunit sequences for L. rubellus, E. fetida, and A. gracilis, (after manual collation to remove allelic variants). AChBPs have been previously described only in molluscs, ${ }^{50,53}$ polychaetes, ${ }^{54}$ and spiders ${ }^{5-57}$ and have not to date been reported in insects. AChBPs are homopentamers formed from $\alpha$-like subunits (Figure 3C) that share high amino acid homology with the extracellular domains of nAChRs. ${ }^{53}$ Each AChBP possesses five sites (Figure 3C) capable of binding acetylcholine ${ }^{58}$ and imidacloprid $^{59}$ but no functional transmembrane domain. ${ }^{53,57}$ The functional role of AChBPs is still unknown, ${ }^{57}$ but they are hypothesized to function away from the synapse, perhaps in nonsynaptic cholinergic communication. ${ }^{50}$ Our analyses indicate that earthworms have an expanded $(\sim 10$ AChBP subunit gene) repertoire compared to those of molluscs (1$\left.2^{53,60}\right)$ and spiders $\left(<5^{57}\right)$. Like nAChRs, AChBP subunit expression is nerve cord biased (SI and Figure S3). AChBPs are highly expressed $(\sim 21 \times$ greater than $\mathrm{nAChR}$ subunits, SI and Figure S3), with the expression dominated by a few very highly expressed orthologues. For these highly expressed AChBPs, we validated the expression using PCR and found high agreement with our RNASeq data (SI and Figure S4). Further, the striking correlation between the total AChBP subunit nerve cord expression and ${ }^{14} \mathrm{C}$-imidacloprid uptake in each species nerve cord supports AChBP-imidacloprid interaction (Figure 4). Thus, highly expressed AChBP orthologues, in addition to nAChR targets, may play important roles in mediating imidacloprid toxicity in earthworms.

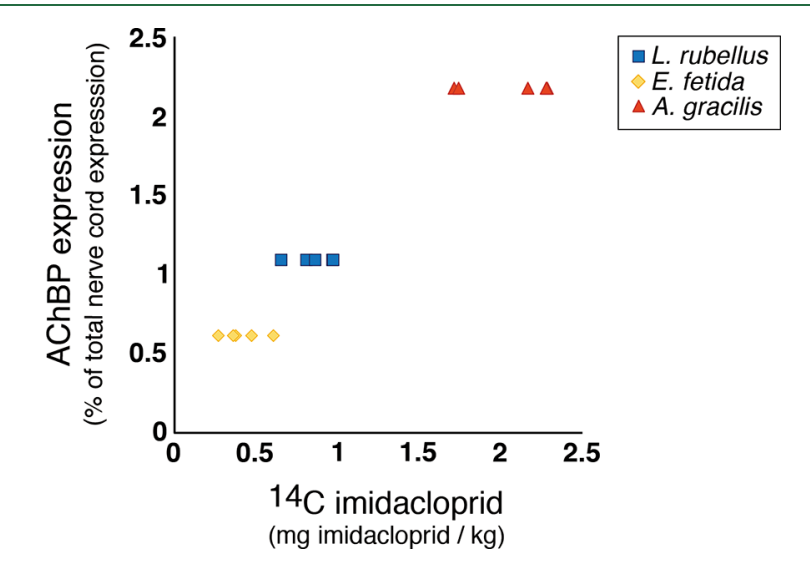

Figure 4. Relative levels of ${ }^{14} \mathrm{C}$-imidacloprid uptake and $\mathrm{AChBP}$ expression in earthworm nerve cords.

Electrophysiological investigations of mutant nAChRs exposed to imidacloprid reveal the influence of critical loop residues on both the receptor peak current $\left(I_{\max }\right)$ and the imidacloprid concentration necessary to activate the receptor to the half maximal level $\left(\mathrm{EC}_{50}\right.$ value). In theory, changes to either property could influence neonicotinoid action. ${ }^{17}$ However, for imidacloprid, a high positive correlation has been found between neurotoxic activity and both its nAChR binding affinity and $\mathrm{EC}_{50}$ value, ${ }^{61,62}$ but no such relationship has been found for $I_{\max }{ }^{62}$ Therefore, while residues altering $I_{\max }$ were characterized (Figures S6-S8 and SI Data S4), our predictions focused on residues shown either to change $\mathrm{EC}_{50}$ or be critical for imidacloprid binding. ${ }^{18}$ (Figure S5 and SI Data S4). Residues at critical sites with uncertain properties were assumed neutral for imidacloprid binding. 
Using full-length contigs, the expression of critical loop residues was determined (see the SI Methods and Results and Discussion approach and detailed quantitative loop analyses). Our analysis covered the $\alpha$ (SI and Figures S6 and S7) and non- $\alpha$ subunits (SI and Figure S8) and all relevant critical residues for each of the less sensitive earthworms $L$. rubellus and E. fetida (collectively termed the lumbricids), the sensitive earthworm A. gracilis, and the known highly sensitive insect $D$. melanogaster $^{63}$ using the published genome and gene expression data for this species. Given their structural homology to nAChRs, ${ }^{18,57}$ we also consider AChBPs as potential off-target binding sites (SI and Figures S9 and S10). For AChBPs, our focus was limited to residues affecting $\mathrm{EC}_{50}$, as residues affecting $I_{\max }$ have no obvious relevance to AChBPs as they are not functioning ion channels. The expression characterization of both nAChRs and AChBPs reveals variations in the expression of critical loop residues between differentially sensitive species. To validate the extent of expression stability at critical residues across multiple samples, we compared expression patterns between the L. rubellus nerve cord and closely related neural ganglia, finding an effectively identical expression across $\mathrm{nAChR}$ and AChBP subunits (Figure S11).

The relative expression of high and low imidacloprid binding residues was used to quantitatively predict a logarithmic affinity score for each interacting loop. A comparison of Drosophila to lumbricids (Figure 5A) and A. gracilis (Figure 5B) suggests, with a single exception, that Drosophila expresses a greater proportion of high-binding residues in nAChR subunit loops, most strikingly for loops $\mathrm{C}$ and $\mathrm{E}$ in $\alpha$ and non$\alpha$ subunits (Figure 5A ,B). In contrast, the lumbricid to $A$. gracilis comparison shows only relatively minor expression differences in high- and low-binding residues across all loops (Figure 5C). Further, even the small expression differences seen are inconsistent and an affinity score in one loop is largely nullified by differences in another (e.g., loops $\mathrm{D}$ and $\mathrm{E}$ in non- $\alpha$ subunits). Unlike for the nAChRs, there are striking differences in the expression of key loop residues in AChBPs between the lumbricids and A. gracilis (Figure 5C). The lumbricids express a greater proportion of AChBPs with high-binding residues, with loops $\mathrm{F}$ and $\mathrm{C}$ presenting the most dramatic differences (Figure 5C). This means that, while A. gracilis may express the highest level of AChBP in the nerve cord, it is predicted to have a weaker binding affinity for imidacloprid.

For nAChRs, it is reasonable to assume that a higher imidacloprid affinity equates to a higher sensitivity, ${ }^{61,62}$ meaning that the calculated affinity score (created by summing the comparative expression proportions of $\mathrm{nAChR}$ loop residues with known effects on imidacloprid binding) equates to a sensitivity score. Calculated scores suggest that differences in $\mathrm{nAChR}$ residues between the three earthworm species and Drosophila (Figure 6A,B) explain DSS between the two taxa. Between the lumbricids and $A$. gracilis, $\mathrm{nAChR}$ residue differences affecting affinity and, thereby, sensitivity appear incapable of accounting for the $>30 \times$ difference in imidacloprid sensitivity (SI and Figure 6). Unlike nAChR, AChBP do not play a critical role in synaptic transmission, instead likely being expressed away from this critical target site with only an ancillary role in synaptic function. It is, therefore, reasonable to assume that a higher AChBP-imidacloprid affinity may equate to a lower sensitivity, as a high affinity to AChBPs will mitigate toxicity via off-target binding, which will in turn reduce $\mathrm{nAChR}$-imidacloprid to reduce nerve

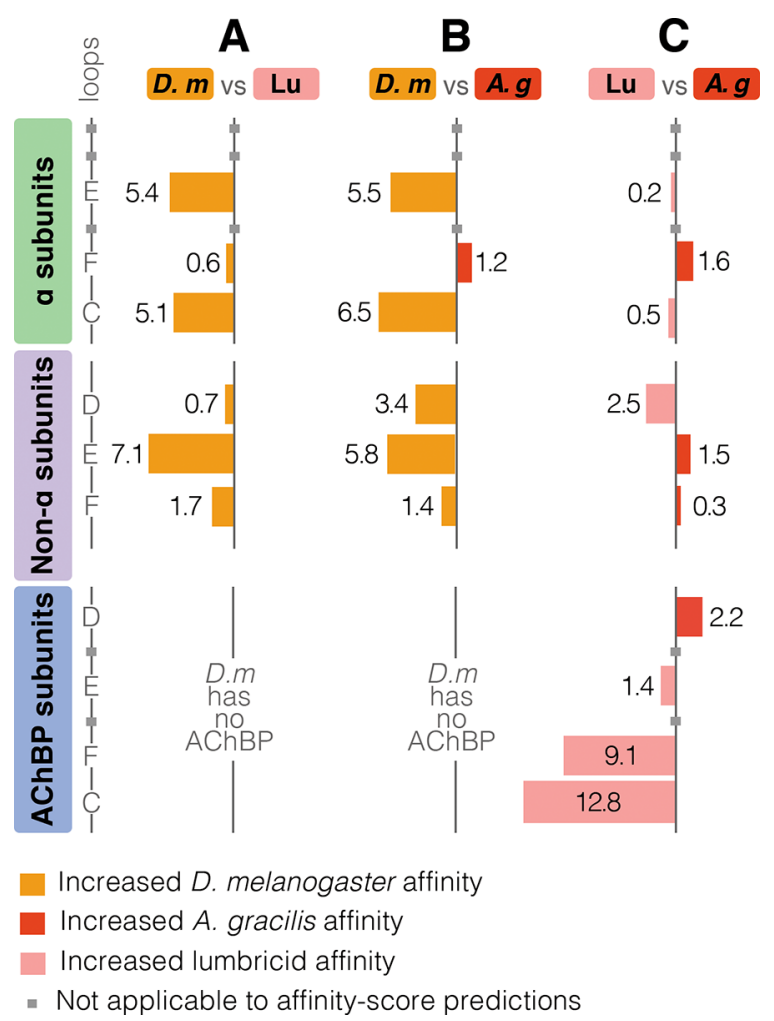

Figure 5. Comparative imidacloprid logarithmic affinity-score predictions for $\mathrm{nAChR}$ and $\mathrm{AChBP}$ subunits based on the expression of variant residues that modulate imidacloprid binding. (A) $D$. melanogaster versus lumbricid earthworms (L. rubellus and E. fetida) predictive comparison across loops in $\mathrm{nAChR}$ subunit ligand binding domains (LBDs). (B) D. melanogaster versus A. gracilis predictive comparison across nAChR subunit LBD loops. (C) Lumbricid earthworms versus $A$. gracilis predictive comparison across $\mathrm{nAChR}$ and AChBP LBD loops.

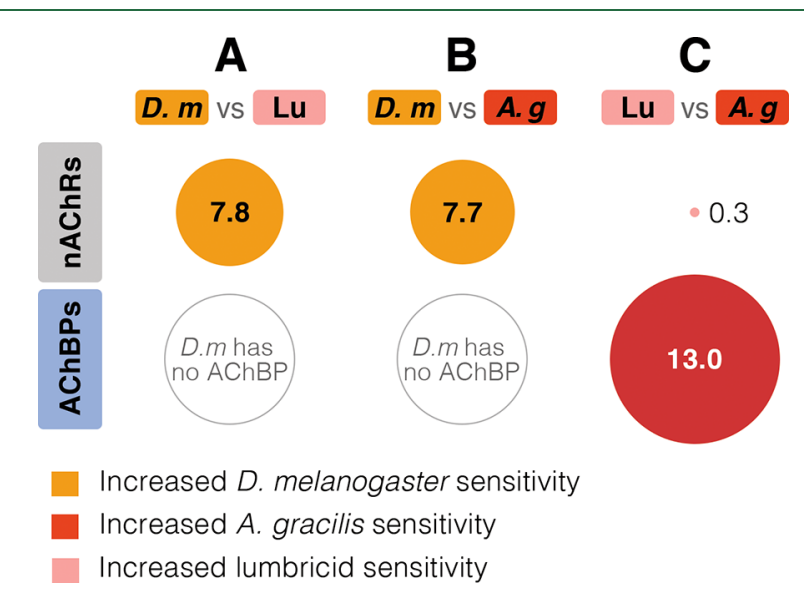

Figure 6. Comparative imidacloprid sensitivity-score predictions based on the affinity scores for nAChR and AChBP subunits. (A) D. melanogaster versus lumbricid earthworms (L. rubellus and $E$. fetida) sensitivity score on the basis of nAChR subunit comparisons. (B) D. melanogaster versus A. gracilis sensitivity score on the basis of nAChR subunit comparisons. (C) Lumbricid earthworms versus $A$. gracilis on the basis of both $\mathrm{nAChR}$ and AChBP subunit comparisons. Sensitivity scores assuming highly expressed $\mathrm{AChBPs}$ represent a less critical target than nAChRs; the low-affinity AChBPs in A. gracilis are predicted to offer less protection for the nAChR, resulting in a predicted higher sensitivity for $A$. gracilis. 
excitation and resulting neurotoxicity. Therefore, for AChBPs, the inverse of the summed affinity score represents a sensitivity score and predicts a high sensitivity of $A$. gracilis relative to that of the lumbricids (Figure 6C), consistent with our observations of actual species sensitivity to imidacloprid (Figure 1A).

Taken overall, the data suggests that nonsynaptic AChBPs play a critical role in determining earthworm sensitivity to imidacloprid. The high expression of AChBPs and the correlation between AChBP expression and the relative 14Cimidacloprid uptake suggest that these proteins dominate the pool of potential imidacloprid targets in earthworms (Figure S3 and Figure 4). We hypothesize that possessing a pool of imidacloprid binding receptors associated with nonsynaptic functionality protects the critical synaptic nAChR target. If correct, this AChBP pool may, in part, contribute to the lower sensitivity of earthworms relative to insects that lack AChBPs. However, it is important to note that we predict the classic $\mathrm{nAChR}$ target also contributes to the differential sensitivity between the taxa (Figure 6), as the comparative affinity scores across the nAChR subunit loops suggest Drosophila nAChRs bind imidacloprid with a greater affinity than their earthworm equivalents (Figure 5). In contrast, our predictions suggest that differences in the classic nAChR target do not underlie the differential sensitivity between earthworms (Figure 6), as the earthworm species are predicted to possess $\mathrm{nAChR}$ repertoires with effectively identical imidacloprid binding affinities (Figure 5). However, unlike the nAChRs, the differential sensitivity between the earthworm species can be explained by the predicted differential binding capacities of their highly expressed AChBP pools. Specifically, the AChBPs in A. gracilis are predicted to have a notably weaker binding affinity for imidacloprid than that of the relatively insensitive lumbricids (Figure 5), meaning that sensitivity is increased (Figure 6) as imidacloprid in nerve tissues of $A$. gracilis can be more readily given up to interact with the primary $\mathrm{nAChR}$ target to cause neurotoxic effects.

The potential for stoichiometric binding of imidacloprid to AChBPs to mitigate primary receptor binding, and as a result toxicity, identified for earthworms could also be important mechanisms for determining DSS in other nontarget taxa. Arachnids also possess AChBPs. ${ }^{55,57}$ Comparative studies have shown that the oribatid mites Oppia nitens has a low sensitivity to imidacloprid compared to insect species, ${ }^{14}$ and neonicotinoids are also known to have a low efficacy against spider mites. ${ }^{64}$ Further, an analogous off-target stoichiometric binding mechanism is proposed to explain resistance development in malarial mosquitos via increased expression of another nontarget protein, the sensory appendage protein SAP2. ${ }^{65}$ Hence, off-target binding may be a common but, until now, unrecognized driver of species DSS of relevance for de novo sensitivity predictions.

Past approaches for predicting sensitivity have focused on the separate roles of TK traits (e.g., internal biotransformation rate $)^{66,67}$ and TD-receptor traits (e.g., presence of known target orthologues). ${ }^{10,68}$ Further, LaLone et al. ${ }^{9}$ have shown that not only just orthologue presence but also the amino acid composition at key motifs can influence DSS. These authors proposed the SeqaPASS approach, which uses the orthologue presence and motif and amino acid sequence information to predict sensitivity. While it is reasonable to suppose that species possessing known target orthologues that interact strongly with a chemical ligand may be sensitive, our study reveals the need for extended analyses, specifically the presence and expression of off-target binding as a potential mechanism for mitigating primary target site interactions. For many cases, truly accurate DSS predictions will require the development of tools capable of comparing and modeling complex, multisubunit, and target (and nontarget) receptor repertoires that are expressed from large and divergent gene families like nAChR subunits. In this paper, we see clear agreement between the observed sensitivity and toxicogenomically generated predictions. This reveals that our innovative but pragmatic approach, exploiting the expression patterns of critical residues in complex receptors, can predict the sensitivity of critical nontarget taxon to environmental toxicants.

\section{ASSOCIATED CONTENT}

\section{Supporting Information}

The Supporting Information is available free of charge at https://pubs.acs.org/doi/10.1021/acs.est.0c05125.

Discussions of earthworm toxicity testing, imidacloprid uptake and distribution, earthworm genotyping, animal dissection and RNA isolation, RT-PCR validation of AChBP expression, assumptions about extrapolating residue function from insects/vertebrates to earthworms, nAChR $\alpha$ subunit and nAChR non- $\alpha$ subunit analyses, summary of $\mathrm{nAChR}$ and $\mathrm{AChBP}$ interaction loop expression differences, AChBP subunit analysis, and off-target binding could mitigate toxicity, table of primer sequences used, and figures of measured versus intended nominal concentrations of imidacloprid, measured imidacloprid in the tissues of L. rubellus exposed for 28 days at different soil concentrations, expression patterns of $\mathrm{nAChR}$ and $\mathrm{AChBP}$ subunits, PCR validation of the nerve cord expression of AChBPs, alignments of $\mathrm{N}$-terminus LBD sequences from Drosophila melanogaster $\mathrm{nAChR}$ subunits with earthworm $\mathrm{nAChR}$ and $\mathrm{AChBP}$ subunits, relative expression proportions of residues in loops $\mathrm{A}, \mathrm{B}$, and $\mathrm{C}$ of $\mathrm{nAChR} \alpha$ subunits, relative expression proportions of residues in loops $G, D, E$, and $\mathrm{F}$ of $\mathrm{nAChR} \alpha$ subunits, relative expression proportions of residues in $\mathrm{nAChR}$ non- $\alpha$ subunits, relative expression proportions of residues in AChBP subunits, and comparison of expression proportions for residues critical to differential imidacloprid binding in the neural ganglion and nerve cord of L. rubellus (PDF)

Dataset of all L. rubellus $\alpha$ nAChR subunits found using reciprocal best BLAST (PDF)

Dataset of all E. fetida $\alpha \mathrm{nAChR}$ subunits found using reciprocal best BLAST (PDF)

Dataset of all $A$. gracilis $\alpha \mathrm{nAChR}$ subunits found using reciprocal best BLAST (PDF)

Dataset of summary of all $n A C h R$ subunits and nAChBP loop residue effects on imidacloprid $I_{\max }$ and $\mathrm{EC}_{50}$ values (XLSX)

\section{AUTHOR INFORMATION}

\section{Corresponding Author}

David J. Spurgeon - UK Centre for Ecology \& Hydrology, Wallingford, Oxfordshire OX10 8BB, United Kingdom; 이이.org/0000-0003-3264-8760; Email: dasp@ ceh.ac.uk 


\section{Authors}

Stephen Short - UK Centre for Ecology \& Hydrology, Wallingford, Oxfordshire OX10 8BB, United Kingdom; Cardiff School of Biosciences, BIOSI 1, University of Cardiff, Cardiff CF10 3TL, United Kingdom; O orcid.org/00000002-6753-933X

Alex Robinson - UK Centre for Ecology \& Hydrology, Wallingford, Oxfordshire OX10 8BB, United Kingdom

Elma Lahive - UK Centre for Ecology \& Hydrology, Wallingford, Oxfordshire OX10 8BB, United Kingdom

Amaia Green Etxabe - UK Centre for Ecology \& Hydrology, Wallingford, Oxfordshire OX10 8BB, United Kingdom

Szabolcs Hernádi - Cardiff School of Biosciences, BIOSI 1, University of Cardiff, Cardiff CF10 3TL, United Kingdom

M. Glória Pereira - UK Centre for Ecology and Hydrology, Bailrigg, Lancaster LA1 4AP, United Kingdom

Peter Kille - Cardiff School of Biosciences, BIOSI 1, University of Cardiff, Cardiff CF10 3TL, United Kingdom

Complete contact information is available at: https://pubs.acs.org/10.1021/acs.est.0c05125

\section{Author Contributions}

"P.K. and D.J.S. contributed equally as senior authors.

\section{Notes}

The authors declare no competing financial interest.

\section{ACKNOWLEDGMENTS}

The work was supported by research grants NE/M01438X/1 and NE/S000135/1 from the UK 533 Natural Environment Research Council (part of UK Research and Innovation) and an Individual 534 Merit Promotion Award supported by Natural Environment Research Council award number 535 NE/R016429/1 through Institutional Fund project NEC06896 for D.J.S. The authors would like to thank Darren Sleep for assistance with the LC-MS for imidacloprid analysis, Luis Cunha for access to the A. gracilis genome, and Nico Van Den Brink for access to scripts for the TK modelling.

\section{REFERENCES}

(1) Milner, A. M.; Boyd, I. L. Toward pesticidovigilance: Can lessons from pharmaceutical monitoring help to improve pesticide regulation? Science 2017, 357 (6357), 1232-1234.

(2) Woodcock, B. A.; Bullock, J. M.; Shore, R. F.; Heard, M. S.; Pereira, M. G.; Redhead, J.; Ridding, L.; Dean, H.; Sleep, D.; Henrys, P.; Peyton, J.; Hulmes, S.; Hulmes, L.; Sarospataki, M.; Saure, C.; Edwards, M.; Genersch, E.; Knabe, S.; Pywell, R. F. Country-specific effects of neonicotinoid pesticides on honey bees and wild bees. Science 2017, 356 (6345), 1393-1395.

(3) Woodcock, B. A.; Isaac, N. J. B.; Bullock, J. M.; Roy, D. B.; Garthwaite, D. G.; Crowe, A.; Pywell, R. F. Impacts of neonicotinoid use on long-term population changes in wild bees in England. Nat. Commun. 2016, 7, 12459.

(4) Tsvetkov, N.; Samson-Robert, O.; Sood, K.; Patel, H. S.; Malena, D. A.; Gajiwala, P. H.; Maciukiewicz, P.; Fournier, V.; Zayed, A. Chronic exposure to neonicotinoids reduces honey bee health near corn crops. Science 2017, 356 (6345), 1395-1397.

(5) Yamamuro, M.; Komuro, T.; Kamiya, H.; Kato, T.; Hasegawa, H.; Kameda, Y. Neonicotinoids disrupt aquatic food webs and decrease fishery yields. Science 2019, 366 (6465), 620-623.

(6) Hladik, M. L.; Main, A. R.; Goulson, D. Environmental risks and challenges associated with neonicotinoid insecticides. Environ. Sci. Technol. 2018, 52 (6), 3329-3335.

(7) Morrissey, C. A.; Mineau, P.; Devries, J. H.; Sanchez-Bayo, F.; Liess, M.; Cavallaro, M. C.; Liber, K. Neonicotinoid contamination of global surface waters and associated risk to aquatic invertebrates: A review. Environ. Int. 2015, 74, 291-303.

(8) Rubach, M. N.; Ashauer, R.; Maund, S. J.; Baird, D. J.; Van den Brink, P. J. Toxicokinetic variation in 15 freshwater arthropod species exposed to the insecticide chlorpyrifos. Environ. Toxicol. Chem. 2010, 29 (10), 2225-2234.

(9) LaLone, C. A.; Villeneuve, D. L.; Lyons, D.; Helgen, H. W.; Robinson, S. L.; Swintek, J. A.; Saari, T. W.; Ankley, G. T. Sequence Alignment to Predict Across Species Susceptibility (SeqAPASS): A Web-Based Tool for Addressing the Challenges of Cross-Species Extrapolation of Chemical Toxicity. Toxicol. Sci. 2016, 153 (2), 228245.

(10) Verbruggen, B.; Gunnarsson, L.; Kristiansson, E.; Osterlund, T.; Owen, S. F.; Snape, J. R.; Tyler, C. R. ECOdrug: a database connecting drugs and conservation of their targets across species. Nucleic Acids Res. 2018, 46 (D1), D930-D936.

(11) Ashauer, R.; Jager, T. Physiological modes of action across species and toxicants: the key to predictive ecotoxicology. Environ. Sci. Process. Impacts 2018, 20, 48-57.

(12) Leist, M.; Ghallab, A.; Graepel, R.; Marchan, R.; Hassan, R.; Bennekou, S. H.; Limonciel, A.; Vinken, M.; Schildknecht, S.; Waldmann, T.; Danen, E.; van Ravenzwaay, B.; Kamp, H.; Gardner, I.; Godoy, P.; Bois, F. Y.; Braeuning, A.; Reif, R.; Oesch, F.; Drasdo, D.; Hohme, S.; Schwarz, M.; Hartung, T.; Braunbeck, T.; Beltman, J.; Vrieling, H.; Sanz, F.; Forsby, A.; Gadaleta, D.; Fisher, C.; Kelm, J.; Fluri, D.; Ecker, G.; Zdrazil, B.; Terron, A.; Jennings, P.; van der Burg, B.; Dooley, S.; Meijer, A. H.; Willighagen, E.; Martens, M.; Evelo, C.; Mombelli, E.; Taboureau, O.; Mantovani, A.; Hardy, B.; Koch, B.; Escher, S.; van Thriel, C.; Cadenas, C.; Kroese, D.; van de Water, B.; Hengstler, J. G. Adverse outcome pathways: opportunities, limitations and open questions. Arch. Toxicol. 2017, 91 (11), 3477-3505.

(13) Blouin, M.; Hodson, M. E.; Delgado, E. A.; Baker, G.; Brussaard, L.; Butt, K. R.; Dai, J.; Dendooven, L.; Peres, G.; Tondoh, J. E.; Cluzeau, D.; Brun, J. J. A review of earthworm impact on soil function and ecosystem services. Eur. J. Soil Sci. 2013, 64 (2), 161182.

(14) Silva, C. D. E.; Brennan, N.; Brouwer, J. M.; Commandeur, D.; Verweij, R. A.; van Gestel, C. A. M. Comparative toxicity of imidacloprid and thiacloprid to different species of soil invertebrates. Ecotoxicology 2017, 26 (4), 555-564.

(15) Pelosi, C.; Joimel, S.; Makowski, D. Searching for a more sensitive earthworm species to be used in pesticide homologation tests - A meta-analysis. Chemosphere 2013, 90 (3), 895-900.

(16) Doering, J. A.; Lee, S.; Kristiansen, K.; Evenseth, L.; Barron, M. G.; Sylte, I.; LaLone, C. A. In silico site-directed mutagenesis informs species-specific predictions of chemical susceptibility derived from the sequence alignment to predict across species susceptibility (SeqaPASS) tool. Toxicol. Sci. 2018, 166 (1), 131-145.

(17) Matsuda, K.; Shimomura, M.; Ihara, M.; Akamatsu, M.; Sattelle, D. B. Neonicotinoids show selective and diverse actions on their nicotinic receptor targets: Electrophysiology, molecular biology, and receptor modeling studies. Biosci., Biotechnol., Biochem. 2005, 69 (8), $1442-1452$.

(18) Ihara, M.; Toshihide, O.; Atsuko, Y.; Takuma, O.; Koichi, H.; Hisashi, N.; Takako, M.; Akamatsu, M.; Ashikawa, Y.; Kuroda, S.; Mega, R.; Kuramitsu, S.; Sattelle, D.; Matsuda, K. Crystal structures of Lymnaea stagnalis AChBP in complex with neonicotinoid insecticides imidacloprid and clothianidin. Invert. Neurosci. 2008, 8 (2), 71-81.

(19) Shimomura, M.; Yokota, M.; Ihara, M.; Akamatsu, M.; Sattelle, D. B.; Matsuda, K. Role in the selectivity of neonicotinoids of insectspecific basic residues in loop $\mathrm{D}$ of the nicotinic acetylcholine receptor agonist binding site. Mol. Pharmacol. 2006, 70 (4), 1255-1263.

(20) Shimomura, M.; Matsuda, K.; Akamatsu, M.; Sattelle, D. B.; Komai, $\mathrm{K}$. Responses to neonicotinoids of chicken alpha 7 nicotinic acetylcholine receptors: Effects of mutations of isoleucine 191 in loop F to aromatic residues. J. Pestic. Sci. 2004, 29 (4), 364-368.

(21) Bass, C.; Puinean, A. M.; Andrews, M.; Cutler, P.; Daniels, M.; Elias, J.; Paul, V. L.; Crossthwaite, A. J.; Denholm, I.; Field, L. M.; Foster, S. P.; Lind, R.; Williamson, M. S.; Slater, R. Mutation of a 
nicotinic acetylcholine receptor beta subunit is associated with resistance to neonicotinoid insecticides in the aphid Myzus persicae. BMC Neurosci. 2011, 12, 51.

(22) Erdmanis, L.; O’Reilly, A. O.; Williamson, M. S.; Field, L. M.; Turberg, A.; Wallace, B. A. Association of neonicotinoid insensitivity with a conserved residue in the loop $\mathrm{d}$ binding region of the tick nicotinic acetylcholine receptor. Biochemistry 2012, 51 (23), 46274629.

(23) PerezLosada, M.; Ricoy, M.; Marshall, J. C.; Dominguez, J. Phylogenetic assessment of the earthworm Aporrectodea caliginosa species complex (Oligochaeta: Lumbricidae) based on mitochondrial and nuclear DNA sequences. Mol. Phylogenet. Evol. 2009, 52 (2), 293-302.

(24) Andre, J.; King, R. A.; Stürzenbaum, S. R.; Kille, P.; Hodson, M. E.; Morgan, A. J. Molecular genetic differentiation in earthworms inhabiting a heterogeneous $\mathrm{Pb}$-polluted landscape. Environ. Pollut. 2010, 158 (3), 883-890.

(25) Anderson, C.; Cunha, L.; Sechi, P.; Kille, P.; Spurgeon, D. Genetic variation in populations of the earthworm, Lumbricus rubellus, across contaminated mine sites. BMC Genet. 2017, 18, 97.

(26) Shekhovtsov, S. V.; Golovanova, E. V.; Peltek, S. E. Different dispersal histories of lineages of the earthworm Aporrectodea caliginosa (Lumbricidae, Annelida) in the Palearctic. Biological Invasions 2016, 18 (3), 751-761.

(27) Novo, M.; Cunha, L.; Maceda-Veiga, A.; Talavera, J. A.; Hodson, M. E.; Spurgeon, D.; Bruford, M. W.; Morgan, A. J.; Kille, P. Multiple introductions and environmental factors affecting the establishment of invasive species on a volcanic island. Soil Biol. Biochem. 2015, 85, 89-100.

(28) Knott, K. E.; Haimi, J. High mitochondrial DNA sequence diversity in the parthenogenetic earthworm Dendrobaena octaedra. Heredity 2010, 105 (4), 341-347.

(29) Robinson, A.; Lahive, E.; Short, S.; Carter, H.; Sleep, D.; Pereira, M. G.; Kille, P.; Spurgeon, D. Chemicals with increasingly complex modes of action result in greater variation in sensitivity between earthworm species. Environ. Pollut. 2020, 115914.

(30) Bart, S.; Amosse, J.; Lowe, C. N.; Mougin, C.; Pery, A. R. R.; Pelosi, C. Aporrectodea caliginosa, a relevant earthworm species for a posteriori pesticide risk assessment: current knowledge and recommendations for culture and experimental design. Environ. Sci. Pollut. Res. 2018, 25 (34), 33867-33881.

(31) Ma, W. C. Sub-lethal toxic effects of copper on growth, reproduction and litter breakdown activity in the earthworm Lumbricus rubellus, with observations on the influence of temperature and soil pH. Environ. Pollut., Ser. A 1984, 33, 207-219.

(32) Ritz, C.; Streibig, J. C. Bioassay analysis using R. J. Stat. Soft. 2005, 12 (5), 1-22.

(33) Spurgeon, D. J.; Lister, L.; Kille, P.; Pereira, M. G.; Wright, J.; Svendsen, C. Toxicokinetic studies reveal variability in earthworm pollutant handling. Pedobiologia 2011, 54, S217-S222.

(34) Carter, L. J.; Garman, C. D.; Ryan, J.; Dowle, A.; Bergstroem, E.; Thomas-Oates, J.; Boxall, A. B. A. Fate and uptake of pharmaceuticals in soil-earthworm systems. Environ. Sci. Technol. 2014, 48 (10), 5955-5963.

(35) Bolger, A. M.; Lohse, M.; Usadel, B. Trimmomatic: a flexible trimmer for Illumina sequence data. Bioinformatics 2014, 30 (15), 2114-2120.

(36) Grabherr, M. G.; Haas, B. J.; Yassour, M.; Levin, J. Z.; Thompson, D. A.; Amit, I.; Adiconis, X.; Fan, L.; Raychowdhury, R.; Zeng, Q. D.; Chen, Z. H.; Mauceli, E.; Hacohen, N.; Gnirke, A.; Rhind, N.; di Palma, F.; Birren, B. W.; Nusbaum, C.; Lindblad-Toh, K.; Friedman, N.; Regev, A. Full-length transcriptome assembly from RNA-Seq data without a reference genome. Nat. Biotechnol. 2011, 29 (7), 644-U130.

(37) Gilbert, D. G. Longest protein, longest transcript or most expression, for accurate gene reconstruction of transcriptomes? bioRxiv 2019, 829184.
(38) Moreno-Hagelsieb, G.; Latimer, K. Choosing BLAST options for better detection of orthologs as reciprocal best hits. Bioinformatics 2008, 24 (3), 319-324.

(39) Ihara, M.; Sattelle, D. B.; Matsuda, K. Probing new components (loop G and the alpha-alpha interface) of neonicotinoid binding sites on nicotinic acetylcholine receptors. Pestic. Biochem. Physiol. 2015, $121,47-52$.

(40) Heugens, E. H. W.; Hendriks, A. J.; Dekker, T.; Van Straalen, N. M.; Admiraal, W. A review of the effects of multiple stressors on aquatic organisms and analysis of uncertainty factors for use in risk assessment. Crit. Rev. Toxicol. 2001, 31 (3), 247-284.

(41) Holmstrup, M.; Bindesbol, A. M.; Oostingh, G. J.; Duschl, A.; Scheil, V.; Kohler, H. R.; Loureiro, S.; Soares, A.; Ferreira, A. L. G.; Kienle, C.; Gerhardt, A.; Laskowski, R.; Kramarz, P. E.; Bayley, M.; Svendsen, C.; Spurgeon, D. J. Interactions between effects of environmental chemicals and natural stressors: A review. Sci. Total Environ. 2010, 408 (18), 3746-3762.

(42) Velki, M.; Ecimovic, S. Changes in exposure temperature lead to changes in pesticide toxicity to earthworms: A preliminary study. Environ. Toxicol. Pharmacol. 2015, 40 (3), 774-784.

(43) Kreutzweiser, D. P.; Good, K. P.; Chartrand, D. T.; Scarr, T. A.; Holmes, S. B.; Thompson, D. G. Effects on litter-dwelling earthworms and microbial decomposition of soil-applied imidacloprid for control of wood-boring insects. Pest Manage. Sci. 2008, 64 (2), 112-118.

(44) Frew, J. A.; Brown, J. T.; Fitzsimmons, P. N.; Hoffman, A. D.; Sadilek, M.; Grue, C. E.; Nichols, J. W. Toxicokinetics of the neonicotinoid insecticide imidacloprid in rainbow trout (Oncorhynchus mykiss). Comp. Biochem. Physiol., Part C: Toxicol. Pharmacol. 2018, 205, 34-42.

(45) Ashauer, R.; Caravatti, I.; Hintermeister, A.; Escher, B. I. Bioaccumulation kinetics of organic xenobiotic pollutants in the freshwater invertebrate Gammarus pulex modeled with prediction intervals. Environ. Toxicol. Chem. 2010, 29 (7), 1625-1636.

(46) Matscheko, N.; Lundstedt, S.; Svensson, L.; Harju, M.; Tysklind, M. Accumulation and elimination of 16 polycyclic aromatic compounds in the earthworm (Eisenia fetida). Environ. Toxicol. Chem. 2002, 21 (8), 1724-1729.

(47) Wagman, N.; Strandberg, B.; Tysklind, M. Dietary uptake and elimination of selected polychlorinated biphenyl congeners and hexachlorobenzene in earthworms. Environ. Toxicol. Chem. 2001, 20 (8), 1778-1784.

(48) Van den Berg, S. J. P.; Baveco, H.; Butler, E.; De Laender, F.; Focks, A.; Franco, A.; Rendal, C.; Van den Brink, P. J. Modeling the sensitivity of aquatic macroinvertebrates to chemicals using traits. Environ. Sci. Technol. 2019, 53 (10), 6025-6034.

(49) Dalhoff, K.; Hansen, A. M. B.; Rasmussen, J. J.; Focks, A.; Strobel, B. W.; Cedergreen, N. Linking morphology, toxicokinetic, and toxicodynamic traits of aquatic invertebrates to pyrethroid sensitivity. Environ. Sci. Technol. 2020, 54 (9), 5687-5699.

(50) Banks, G.; Kemenes, I.; Schofield, M.; O’Shea, M.; Korneev, S. A. Acetylcholine binding protein of mollusks is unlikely to act as a regulator of cholinergic neurotransmission at neurite-neurite synaptic sites in vivo. FASEB J. 2009, 23 (9), 3030-3036.

(51) Jones, A. K.; Sattelle, D. B. Diversity of insect nicotinic acetylcholine receptor subunits. In Insect Nicotinic Acetylcholine Receptors; Thany, S. H., Ed.; Springer: New York, NY, 2010; Vol. 683, pp 25-43.

(52) Pedersen, J. E.; Bergqvist, C. A.; Larhammar, D. Evolution of vertebrate nicotinic acetylcholine receptors. BMC Evol. Biol. 2019, 19, 38.

(53) Smit, A. B.; Syed, N. I.; Schaap, D.; van Minnen, J.; Klumperman, J.; Kits, K. S.; Lodder, H.; van der Schors, R. C.; van Elk, R.; Sorgedrager, B.; Brejc, K.; Sixma, T. K.; Geraerts, W. P. M. A glia-derived acetylcholine-binding protein that modulates synaptic transmission. Nature 2001, 411 (6835), 261-268.

(54) McCormack, T.; Petrovich, R. M.; Mercier, K. A.; DeRose, E. F.; Cuneo, M. J.; Williams, J.; Johnson, K. L.; Lamb, P. W.; London, R. E.; Yakel, J. L. Identification and functional characterization of a 
novel acetylcholine-binding protein from the marine annelid Capitella teleta. Biochemistry 2010, 49 (10), 2279-2287.

(55) Torkkeli, P. H.; Liu, H. X.; French, A. S. Transcriptome analysis of the central and peripheral nervous systems of the spider Cupiennius salei reveals multiple putative cys-loop ligand gated ion channel subunits and an acetylcholine binding protein. PLoS One 2015, 10 (9), No. e0138068.

(56) Liu, H. X.; French, A. S.; Torkkeli, P. H. Expression of Cys-loop receptor subunits and acetylcholine binding protein in the mechanosensory neurons, glial cells, and muscle tissue of the spider Cupiennius salei. J. Comp. Neurol. 2017, 525 (5), 1139-1154.

(57) Bao, H. B.; Meng, X. K.; Liu, Z. W. Spider acetylcholine binding proteins: An alternative model to study the interaction between insect $\mathrm{nAChRs}$ and neonicotinoids. Insect Biochem. Mol. Biol. 2017, 90, 82-89.

(58) Brejc, K.; van Dijk, W. J.; Klaassen, R. V.; Schuurmans, M.; van der Oost, J.; Smit, A. B.; Sixma, T. K. Crystal structure of an AChbinding protein reveals the ligand-binding domain of nicotinic receptors. Nature 2001, 411 (6835), 269-276.

(59) Ihara, M.; Hikida, M.; Matsushita, H.; Yamanaka, K.; Kishimoto, Y.; Kubo, K.; Watanabe, S.; Sakamoto, M.; Matsui, K.; Yamaguchi, A.; Okuhara, D.; Furutani, S.; Sattelle, D. B.; Matsuda, K. Loops D, E and G in the Drosophila D1 subunit contribute to high neonicotinoid sensitivity of D1-chicken 2 nicotinic acetylcholine receptor. Br. J. Pharmacol. 2018, 175 (11), 1999-2012.

(60) Saur, M.; Moeller, V.; Kapetanopoulos, K.; Braukmann, S.; Gebauer, W.; Tenzer, S.; Markl, J. Acetylcholine-binding protein in the hemolymph of the planorbid snail Biomphalaria glabrata is a pentagonal dodecahedron (60 subunits). PLoS One 2012, 7, e43685.

(61) Liu, M. Y.; Casida, J. E. High-affinity binding of H-3 imidacloprid in the insect acetylcholine-receptor. Pestic. Biochem. Physiol. 1993, 46 (1), 40-46.

(62) Nishiwaki, H.; Nakagawa, Y.; Kuwamura, M.; Sato, K.; Akamatsu, M.; Matsuda, K.; Komai, K.; Miyagawa, H. Correlations of the electrophysiological activity of neonicotinoids with their binding and insecticidal activities. Pest Manage. Sci. 2003, 59 (9), $1023-1030$

(63) Graveley, B. The developmental transcriptome of Drosophila melanogaster. Genome Biol. 2010, 11, I11.

(64) Smith, J. F.; Catchot, A. L.; Musser, F. R.; Gore, J. Effects of aldicarb and neonicotinoid seed treatments on twospotted spider mite on cotton. J. Econ. Entomol. 2013, 106 (2), 807-815.

(65) Ingham, V. A.; Anthousi, A.; Douris, V.; Harding, N. J.; Lycett, G.; Morris, M.; Vontas, J.; Ranson, H. A sensory appendage protein protects malaria vectors from pyrethroids. Nature 2020, 577 (7790), 376-380.

(66) Selck, H.; Palmqvist, A.; Forbes, V. E. Biotransformation of dissolved and sediment-bound fluoranthene in the polychaete, Capitella sp I. Environ. Toxicol. Chem. 2003, 22 (10), 2364-2374.

(67) Bach, L.; Palmqvist, A.; Rasmussen, L. J.; Forbes, V. E. Differences in PAH tolerance between Capitella species: Underlying biochemical mechanisms. Aquat. Toxicol. 2005, 74 (4), 307-319.

(68) Gunnarsson, L.; Jauhiainen, A.; Kristiansson, E.; Nerman, O.; Larsson, D. G. J. Evolutionary conservation of human drug targets in organisms used for environmental risk assessments. Environ. Sci. Technol. 2008, 42 (15), 5807-5813. 